e-Neuroforum $2011 \cdot 2: 68-77$

DOI 10.1007/s13295-011-0021-6

(C) Springer-Verlag 2011

\author{
I. Manzini ${ }^{1} \cdot$ S. Korsching ${ }^{2}$ \\ ${ }^{1}$ DFG Research Center Molecular Physiology of the Brain (CMPB), Department of \\ Neurophysiology and Cellular Biophysics, University of Göttingen, Göttingen \\ ${ }^{2}$ Institute for Genetics, University of Cologne, Cologne
}

\title{
The peripheral olfactory system of vertebrates: molecular, structural and functional basics of the sense of smell
}

\section{Introduction}

Olfaction is a phylogenetically ancient sense; its origins lie in the detection of environmental chemicals and go back to bacterial chemotaxis. In a more narrow sense olfaction is defined as a specialized sense of, among others, vertebrates and arthropods, which is distinct from the second specialized chemosensory sense, gustation, in terms of both molecular and anatomical features. In first approximation the sense of smell is distinguished from the sense of taste by higher sensitivity and analytical instead of categorizing signal processing. This review describes the initial processes in the perception of odors, up to and including the neuronal representation of odors in the olfactory bulb.

\section{Structure and evolution of olfactory receptor genes}

During the evolution of vertebrates successive families of olfactory receptor genes came into being or were recruited from already existing families as olfactory receptor genes, usually leading to a pronounced expansion of the respective gene family. Olfactory receptor gene families generally show a dynamic evolution and correspondingly high species specificity of their receptor repertoires. Indeed, evidence for the positive selection of olfactory receptor genes, i.e. selection for diversity of these genes, has been found. Currently five such olfactory receptor gene families are known for vertebrates (• Fig. 1), which in many species have been predicted by bioinformatic searches of whole genome sequences [30, 39].

The first olfactory receptor gene family to be discovered received the generic name 'odorant receptors' (ORs). Two families of vomeronasal receptors have been named according to their expression site in mammals ( $\mathrm{V}_{1} \mathrm{R}$ and $\mathrm{V}_{2} \mathrm{R}$, their homologues in fish are sometimes called ORA and OlfC genes, respectively). A family of aminergic receptors, the so-called trace amine-associated receptors (TAARs), are named according to some of their ligands, and finally formylpeptide receptors (FPRs) were identified as olfactory receptors just 2 years ago, in 2009 [39, $49,65]$. Vomeronasal receptors are sometimes designated as pheromone receptors and as such distinguished from olfactory receptors proper. However, in the light of current knowledge this distinction appears largely artificial and will not be considered further for the purpose of this review. Pheromones are organic molecules that serve biochemical communication within a species (interspecies messenger molecules have been designated as kairomones), in other words, their difference to 'normal' odor substances (odorants) is not necessarily contained in their chemical nature or their receptors, but many processing steps later in the coupling to particular behaviors. With the exception of the metabotropic glutamate receptorlike $V_{2} R$ genes, which are $\mathrm{G}$ protein-coupled receptors (GPCRs) from group C, all other families belong to the rhodopsin- like group A of GPCRs or are group Arelated genes ( $\left.\mathrm{V}_{1} \mathrm{Rs}\right)$. Most olfactory receptor genes are monoexonic, except for some representatives of the $\mathrm{V}_{1} \mathrm{R} / \mathrm{ORA}$ gene family in teleost fishes and the $\mathrm{V}_{2} \mathrm{R}$ genes, which share a characteristic six exon structure with closely related gene families.

The extent of a family may vary between zero and several hundred members in different species (• Fig. 1; see e.g. [21]). The record is held by the OR family, with over 1000 functional genes in rodents [39]. The hypothesis that the size of the olfactory receptor repertoire corresponds to the importance of the sense of smell in the respective species is difficult to test, among other reasons because deorphanization of receptors has proven to be a difficult task. Family sizes have been influenced by three whole genome duplications during vertebrate development, the third one restricted to the teleost branch of the phylogenetic tree (see [3o]). However, frequent gene losses and local gene duplications contribute more to variability in family sizes, the latter leading to the often observed arrangement of olfactory receptor genes in large clusters in the genome. Both effects taken together can result in very different family sizes even in closely related species. For example, humans possess not a single intact $V_{2} R$ gene and only few pseudogenes, whereas the mouse genome contains nearly 100 intact $\mathrm{V}_{2} \mathrm{R}$ genes and twice as many pseudogenes $[39,59,71]$. The frequency of pseudogenes is often very high, presum- 
ably because the loss of individual receptors does not usually constitute a selective disadvantage. However, it should be mentioned that concrete numbers for pseudogene frequencies depend very much on the quality of the databases and prediction algorithms used.

The V1R-related ORA genes in fish show a drastically different mode of evolution. This is a small family of six highly conserved genes, all of which may have existed already before the divergence of bony fish from cartilaginous fish. In other words, neither the last teleost-specific whole genome duplication nor local gene duplications had an influence on the size of this receptor family [53].

The five receptor gene families originated, or were co-opted, by the olfactory system at different time points during the evolution of vertebrates. Phylogenetically oldest are the OR and $\mathrm{V}_{1} \mathrm{R}$ families, which each possessed several members already before the divergence of jawed from jawless fish (e.g. lamprey). In contrast, the first representatives of the TAAR and $V_{2} R$ families were found in cartilaginous fish (shark), but not in lamprey (• Fig. 1). Interestingly, a group of TAAR-related aminergic genes were already recruited as olfactory receptor genes in lamprey [4, 21], presumably independent of the TAAR genes. The evolutionarily youngest addition are the FPR genes, which developed in mammals as an immunologically relevant receptor group, but have been coopted as olfactory receptor genes only in rodents $[33,49]$.

Finally, it should be mentioned that there are also two members of the membrane-bound guanylate cyclase gene family in discussion as olfactory receptor genes [65]. This family is phylogenetically considerably older than the five GPCR families discussed here and invertebrate members already possess chemosensory functions.

\section{Expression patterns of olfactory receptor genes and mechanism of expression}

The overwhelming majority of previous experiments have shown monogenic expression of olfactory receptor genes, i.e. a particular olfactory receptor neuron ex-

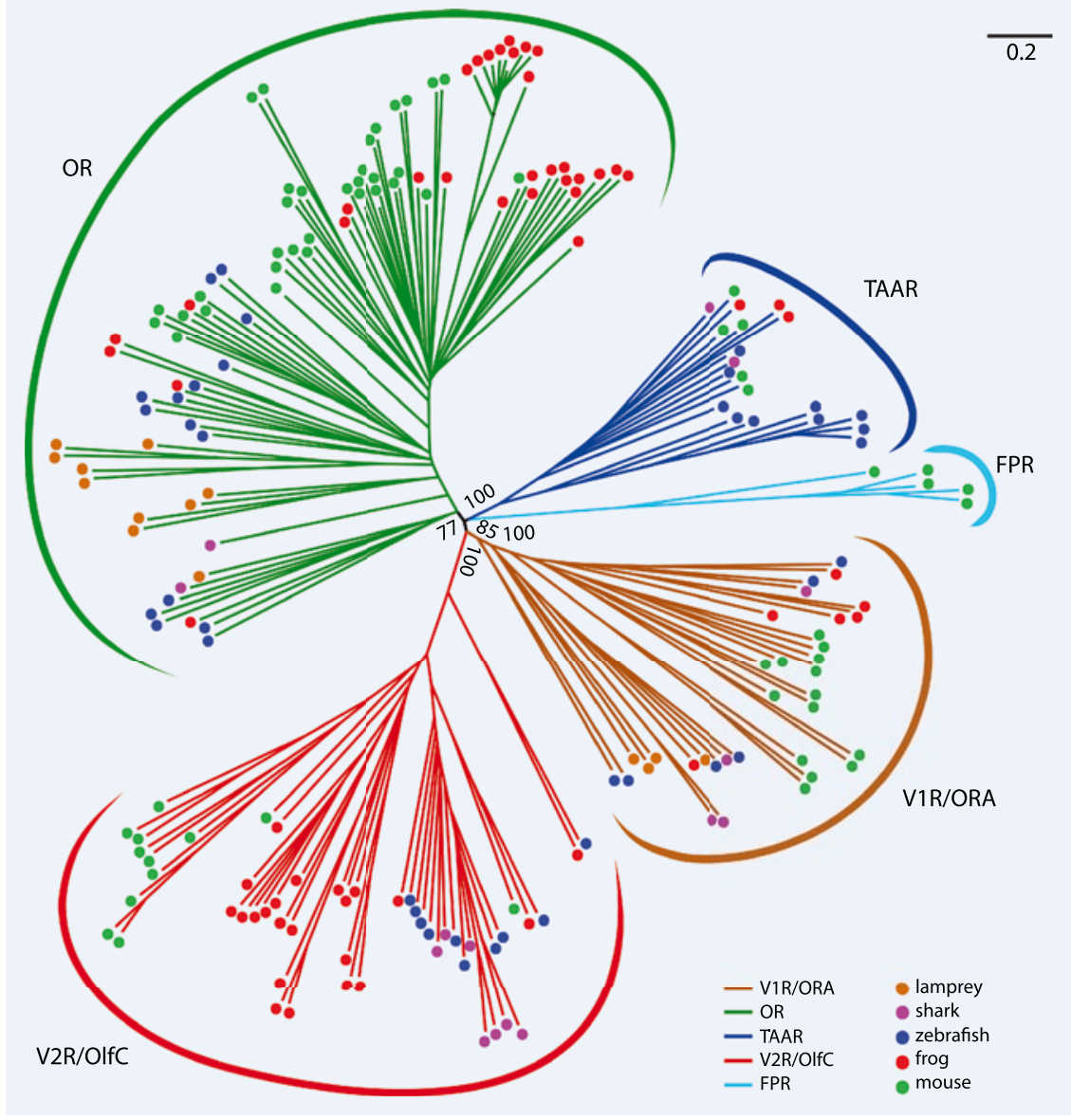

Fig. $1 \Delta$ The evolutionary relationship of olfactory receptor genes. The phylogenetic tree shows the relationship of five GPCR receptor gene families. OR odorant receptors, TAAR trace amine-associated receptors, V1R and V2R vomeronasal receptors type 1 and 2, ORA V1R-homologous fish receptors, OlfC V2R-homologous fish receptors, FPR formylpeptide receptors. For the sake of clarity a random selection of receptors (approximately the square root of total numbers) has been used for gene families surpassing 20 genes. Species are color-coded; blue zebrafish, a teleost, red clawed frog, an amphibian, green mouse, a mammal, magenta elephant shark, a cartilaginous fish, brown lamprey, a jawless fish. Protein sequences were aligned with MAFFT and the tree was calculated using the $\mathrm{NJ}$ algorithm and 1000 bootstrap cycles

presses only a single receptor gene from one of the five families. Neighboring receptor neurons generally express different receptors leading to the characteristic spotted expression pattern.

Due to this monogenic expression the response characteristics of an olfactory receptor neuron should resemble those of the receptor expressed by it. Thus, the number of different receptor genes determines the number of subpopulations of receptor neurons, and consequently the number of input channels to the olfactory bulb, the first brain region concerned with processing olfactory information. In mice this number includes about 1000 individual receptor genes from the OR family alone, plus several hundred genes from the other four families $[26,39]$.
Monogenic expression, also known as the one neuron-one receptor rule, poses an interesting problem for the regulation of gene expression, since every single neuron has to make a choice which receptor to express from a large number of equivalent receptor genes. The mechanisms involved are complex, and several observations point to the existence of a multilevel process (see also [1]). Different types of olfactory receptor neurons (see below) express different families of olfactory receptor genes, which points to the existence of family-specific regulatory elements (notwithstanding exceptions to the rule in each of the families). Moreover, the expression of individual receptor genes within a family is restricted to subregions of the olfactory epithelium, so-called ex- 


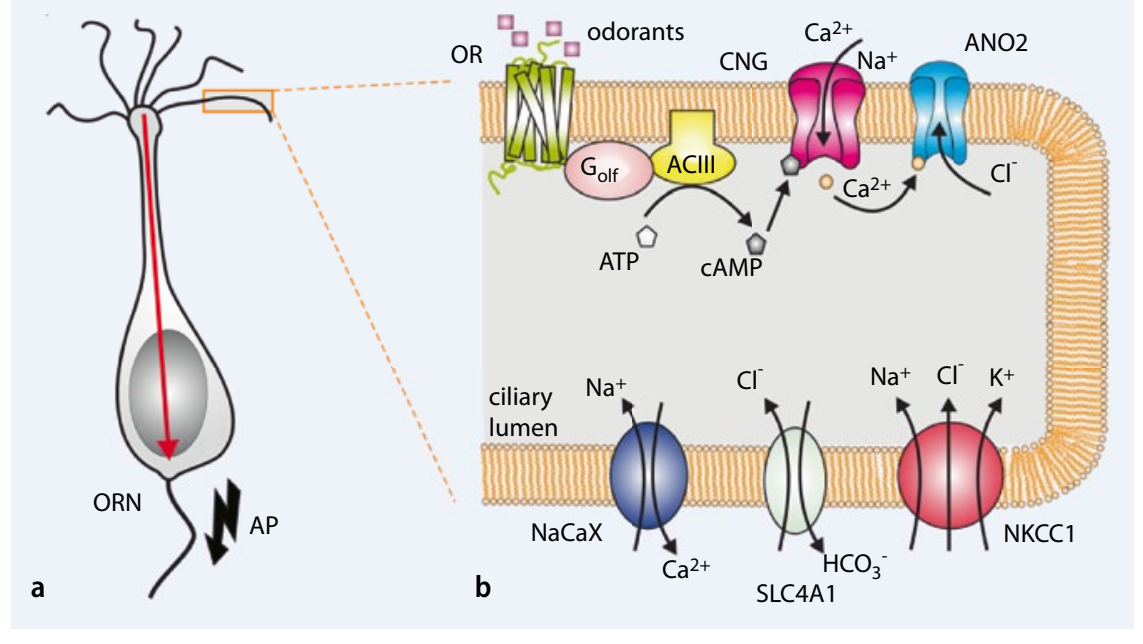

Fig. $2 \Delta$ Signal transduction cascade of OR olfactory receptors. a An olfactory receptor neuron (ORN). ORNs are bipolar neurons, whose dendrite rises to the surface of the olfactory epithelium, with a dendritic knob from which sensory, nonmotile cilia emerge. The cilia are the main site of olfactory signal transduction (see b). The receptor potential generated by the signal transduction is propagated electrotonically (red arrow) to the axon hillock, where a volley of action potentials $(A P)$ is elicited when the opening threshold of voltage-gated $\mathrm{Na}^{+}$-ion channels is exceeded. $\mathbf{b}$ An olfactory cilium illustrating the processes that occur upon binding of an odorant to an olfactory receptor and showing how the ion concentrations within the cilium are restored to resting levels after stimulation. A detailed description of these processes is given in the main text. ANO2 calcium-activated chloride channel, $A C I I I$ adenylate cyclase type 3, ATP adenosine trisphosphate, CAMP cyclic adenosine monophosphate, CNG cyclic nucleotide-gated ion channel, $G_{\text {olf }}$ olfactory G protein, $\mathrm{NaCaX} \mathrm{Na}{ }^{+} / \mathrm{Ca}^{2+}$ exchanger, $\mathrm{NKCC} 1 \mathrm{Na}^{+}$/ $\mathrm{K}^{+} / 2 \mathrm{Cl}^{-}$co-transporter, $\mathrm{SLC}_{\mathrm{CA}} 1 \mathrm{Cl}^{-} / \mathrm{HCO}_{3}{ }^{-}$exchanger

pression zones or domains. These subregions may segregate rather strictly, such as those for the mammalian class I and class II OR genes, but can also show massive overlap, particular in, but not limited to, lower vertebrates $[37,69]$. Finally, the scattered distribution of neurons expressing the same olfactory receptor points to a stochastic element in the regulation of expression.

Until recently it was assumed that negative feedback from the chosen receptor inhibits the expression of other receptor genes [42, 58]. Furthermore, long-range enhancer regions have been detected (H region, [57]) that may implement restriction of expression to a single gene at least from the group of genes under the influence of this enhancer. However, it has been shown very recently that olfactory receptor genes in (and only in) olfactory receptor neurons are generally repressed by a particular histone methylation [35]. It could be argued that overcoming this general repression may be a very unlikely, i.e. rare event. In this case one would expect occasional co-expression of receptor genes, but below a frequency of 0.001 [62] . Monogenic expression has also been demonstrated for zebrafish, although the co- expression of closely related members of an OR subfamily could point to a less restrictive mechanism for regulation of expression in lower vertebrates [55].

Mammalian olfactory receptor genes show not only monogenic, but also rather strict monoallelic expression, with a coexpression of both parental alleles found in only one per mille of all neurons examined. Different alleles may vary in their ligand binding spectra [28], and so monoallelic expression may also serve to restrict the response properties of receptor neurons. Contrary to former expectations monoallelic expression is actually widespread in the genome, and its mechanism could be, but does not have to be, different from that ensuring monogenic expression $[35,40,42]$.

Deviating from the expression patterns described above a pairwise co-expression of members of a $V_{2} R$ subfamily each with a single receptor gene from the other subfamilies is observed [23]. A broad expression of the homologous zebrafish genes (OlfCa1, OlfCc1) would seem to indicate a similar co-expression with the specifically expressed OlfC genes. The function of this co-expression is not known, but may be similar to that of the similarly broadly expressed OR83b of insects (see article by Sachse and Krieger, this issue).

\section{Ligand binding properties of olfactory receptors}

The binding properties of receptors define the space of possible odorants. In principle each odorant and each odorant mixture can be assigned a point representation in a virtual odor space spanned by the existing olfactory receptors as axes of that odor space. In practice such a representation is not feasible, since very few olfactory receptors have been hitherto de-orphanized $[39,51]$. One of the problems encountered with ligand identification certainly is the multitude of possible odorants, but technical problems are also massive, in particular the generally inefficient expression of olfactory receptors in heterologous systems due to intracellular transport problems. However, among other measures, co-expression of transporter molecules and the introduction of efficient signal sequences have steadily improved the expression rates of olfactory receptors in heterologous systems (see $[39,51])$.

Results obtained to date show that the majority of de-orphanized receptors exhibit a pronounced specificity for just a few ligands, which are often, but not always, related in their chemical structure $[39,51]$. Conversely, individual ligands are predominantly recognized by more than one receptor, whose affinities may differ by several orders of magnitude [39, 51]. These features result in combinatorial coding such that particular odorants are each represented by different and unique combinations of activated receptors.

In contrast to this predominant mode of operation, some receptors, in particular pheromone receptors, are extremely specific and recognize only a single odorant from among all those tested (see [15]), while others are remarkable by their unusually broad spectrum of ligands, e.g. SR1 [14], the main receptor of the septal organ. Our understanding of odorant receptor interaction is in its infancy, since structural analysis so far has had to contend with modelling and mutational analyses, which moreover have been performed with only a handful of olfactory receptors to date 
(see [25]). The best understood example may be the I7 receptor [31], whose rat orthologue is optimally activated by an aliphatic aldehyde of moderate chain length (n-octanal). There have been several descriptions of substances serving as competetive antagonists for other odorants, blocking them without acting as odorant themselves. The antagonist status depends on the particular G-protein coupling to the receptor [6o], which may serve as a first indication into the nature of further molecular processes after binding the odorant. However, the exact nature of those intramolecular events transducing the binding of an odorant to the activation of its receptor is not known for any odorant receptor.

The chemical spectrum of odorants is very broad and encompasses gases $\left(\mathrm{H}_{2} \mathrm{~S}\right.$; $\mathrm{CO}_{2}$, perceived as bicarbonate, receptors GC-D and GC-G; [10, 63]), manifold lowmolecular weight substances, some of them with pheromone character (among them aldehydes, amines, amino acids, alcohols, bile acids, nucleotides), as well as peptides (among others MHC peptides perceived by $\mathrm{V}_{2} \mathrm{R}$ receptors). Non-volatile compounds in this list are either taken up by direct contact or serve as odorants only in aquatic species.

\section{Olfactory receptor neurons}

Olfactory receptor neurons in vertebrates are bipolar neurons with an axon projecting into the olfactory bulb and a dendrite that ends in a so-called dendritic knob. This knob carries non-motile cilia or microvilli, which are specialized structures serving olfactory perception. In mammals these types of receptor neurons are situated in separate olfactory organs, the ciliated neurons in the main olfactory epithelium and the septal organ, named after its location on the septum; ciliated neurons of a different morphology in the extremely anteriorly situated Grüneberg ganglion, and two anatomically and functionally distinct populations of microvilllous neurons in the bilayered vomeronasal olfactory epithelium (apical and basal layer). In contrast, fish do not exhibit separate olfactory organs but a single olfactory epithelium which harbors both ciliated and microvillous receptor neurons. The spatial segregation of cell types begins in amphibians, which possess a vomeronasal organ with microvillous receptor neurons, but still exhibit microvillous neurons in the main olfactory epithelium in many species.

A third type of olfactory receptor neurons, the so-called crypt cells, shows a globular morphology, no recognizable dendrite and the simultaneous presence of cilia and microvilli. So far it has only been found in fish, although there is at least a superficial morphological similarity to the ciliated neurons of the Grüneberg ganglion.

Notwithstanding some exceptions the five olfactory receptor gene families are specifically expressed in particular subpopulations of receptor neurons. The OR family is overwhelmingly expressed in ciliated receptor neurons of the main olfactory epithelium, as is the TAAR family. However, a few ORs are also expressed in the septal organ, the Grüneberg ganglion and the vomeronasal organ, and a few TAARs are also found in the Grüneberg ganglion. $V_{1} R, V_{2} R$ and FPR genes are expressed in microvillous receptor neurons, a particular $\mathrm{V}_{2} \mathrm{R}$ receptor also in the Grüneberg ganglion [43]. OR and $\mathrm{V}_{2} \mathrm{R}$-homologous OlfC genes in fish are correspondingly expressed in ciliated and microvillous receptor neurons, respectively [54].

Due to the monogenic expression of olfactory receptor genes the response properties of receptor neurons are expected to resemble those of the underlying receptor molecules, at least in first approximation. Indeed, one finds predominantly combinatorial representation of odorants at the level of receptor neurons, as observed for receptor molecules, and again with widely differing affinities for the same odorant [45]. Occasionally, highly specific receptor neurons are found, usually reacting to pheromones or kairomones [45].

\section{CAMP-mediated signal transduction in mammalian olfactory receptor neurons}

The transduction cascade of OR olfactory receptors has been studied extensively in mammalian ciliated receptor neurons (• Fig. 2; [20, 26]). Binding of an odor-
e-Neuroforum $2011 \cdot 2: 68-77$

DOI 10.1007/s13295-011-0021-6

c) Springer-Verlag 2011

\section{Manzini $\cdot$ S. Korsching}

The peripheral olfactory system of vertebrates: molecular, structural and functional basics of the sense of smell

\section{Abstract}

The sense of smell provides people and animals with an abundance of information about their environment, helping them to navigate, detect potential threats, control food intake, choose sexual partners and significantly influence intraspecies social behavior. The perception of odors begins with the binding of odor molecules to specialized olfactory receptor proteins, which nearly all belong to the superfamily of $G$ protein-coupled receptors. Altogether, five different olfactory receptor gene families have been described to date, among them the largest gene family in the genome with over 1000 genes in rodents. The signal transduction cascade coupled to the receptors has already been well characterized for this family. Three different classes of receptor neurons-ciliated, microvillous and crypt receptor neurons - can be distinguished by their anatomical and molecular characteristics. Generally, an individual receptor neuron expresses only a single olfactory receptor gene, and olfactory receptor neurons that express the same receptor converge into a common target structure, a glomerulus, which generates a receptotopic map in the first olfactory brain region, the olfactory bulb. This review article provides a general overview of the peripheral detection of odorants on the one hand, while on the other it focuses on recent advances in the field, including new findings on the peripheral modulation of olfactory signals.

\section{Keywords}

Olfactory receptor neurons - Odorant receptor · Signal transduction · Olfactory wiring $\cdot$ Behaviour 
ant to a receptor leads to the activation of a specific olfactory $\mathrm{G}$ alpha protein $\left(\mathrm{G}_{\mathrm{olf}}\right)$, which itself activates a membrane-localized adenylate cyclase of type III. cAMP generated by this cyclase binds to non-selective CNG channels (cyclic nucleotidegated), opening them in the process. $\mathrm{Na}^{+}$ and $\mathrm{Ca}^{2+}$ ions from the mucus layer of the olfactory epithelium flow into the ciliary lumen, leading to a depolarization of the ciliary membrane and therefore to a receptor potential. Inflowing $\mathrm{Ca}^{2+}$ ions then open calcium-activated chloride channels, which allow $\mathrm{Cl}^{-}$ions to leave the ciliary lumen and pass into the mucus layer. The molecular identification of these chloride channels has been tedious, but finally Ano2/TMEM16b was identified as the chloride ion channel of ciliated (and microvillous) receptor neurons, after previous assumptions about a member of the bestrophin family playing a role were not borne out. Chloride channels were supposed to amplify the CNG-generated signal about tenfold, but doubt has arisen, since an ano2 knockout was able to block the chloride efflux completely, but did not generate a significant reduction of the overall signal transduction [6].

Several different transporters are involved in restoring the electrochemical gradients to their resting state values, both for chloride ions and mono- and divalent cations. Chloride ions are transported back into the ciliary lumen by a $\mathrm{Na}^{+} / \mathrm{K}^{+} / 2 \mathrm{Cl}^{-}$co-transporter (NKCC 1 ) and a $\mathrm{Cl}^{-} / \mathrm{HCO}_{3}{ }^{-}$exchanger ( $\mathrm{SLC}_{4} \mathrm{~A} 1$ ) expressed in the ciliary membrane. Calcium ions are transported out of the ciliary lumen by a $\mathrm{Na}^{+} / \mathrm{Ca}^{2+}$ exchanger $(\mathrm{Na}-$ CaX; $\bullet$ Fig. 2).

cAMP-mediated signal transduction of this kind is also found for the OR receptors of the septal organ, the TAAR receptors of the main olfactory epithelium and, interestingly, also the five human $V_{1} R$ receptors, which seem to have escaped the pseudogenization of this family in primates by a shift of their expression into the main olfactory epithelium $[43,50,61]$.

\section{Other signal transduction pathways in mammalian olfactory receptor neurons}

Instead of the cAMP-mediated transduction cascade, alternative transduction mechanisms are observed in smaller subpopulations of neurons in the mammalian main olfactory epithelium. These include a phospholipase C (PLC), transient receptor potential (TRP) ion channels TRPC6 and TRPM5, as well as a receptor guanylate cyclase (GC-D), together with a cGMP-dependent CNG ion channel [43].

Both microvillous neuron populations of the mammalian vomeronasal organ signal via PLC, not via adenylate cyclase as the ciliated neurons of the main olfactory epithelium do. Apical neurons express $V_{1} R$ receptors and $G_{i}$ as $G$ protein, whereas the basal neurons express $V_{2} \mathrm{R}$ receptors and $G_{0}$. The activation of PLC generates inositoltrisphosphate $\left(\mathrm{IP}_{3}\right)$, diacylglycerol (DAG) and arachidonic acid, followed by an activation of TRPC2 channels. A very small subpopulation of vomeronasal receptor neurons expresses OR receptors, which nevertheless couple to $G_{i}$ and TRPC2, not to $G_{\text {olf }}$ and ACIII, as would be typical for the OR family [43]. Similarly, signal transduction of TAAR receptors expressed in the Grüneberg ganglion is via $G_{i}$, and $G_{0}$, like that of the $V_{2} R$ receptors expressed there and unlike the TAAR signal transduction in the main olfactory epithelium, which proceeds via $\mathrm{G}_{\mathrm{olf}}$ and cAMP [43]. These observations seem to indicate that the selection of the signal transduction pathway is determined first and foremost by the type of receptor neuron, not by the receptor molecule, and that some receptor families can couple to different signal transduction cascades.

\section{Olfactory signal transduction in lower vertebrates}

The two main mammalian transduction pathways are conserved in amphibians and fish. Central components of the cAMP-mediated signal transduction such as the $\mathrm{G}$ protein $\mathrm{G}_{\text {olf }}$ and the cAMP-gated CNG channel were detected in ciliated receptor neurons of zebrafish, whereas microvillous receptor neurons express $G_{0}$ and the TRPC2 ion channel $[17,46,54,70]$. However there may be some species differences concerning $G$ proteins [17]. For crypt neurons, the third type of olfactory receptor neurons, $G_{\text {olf }}$ has not been detected, but three different $G$ proteins, $G_{i}$, $G_{o}$ and $G_{q}$ have been reported for different species [17]. These results show that non cAMP-mediated transduction pathways are widespread in fish. Similarly, in the clawed frog Xenopus laevis there are at least two different populations of neurons, one with the classical cAMP-mediated pathway, and the other with CAMP-independent signal transduction [36].

\section{Adaptation of signal transduction}

To enable a fast reaction of the organism to changing stimuli it is essential to rapidly switch off the signal transduction cascade. Indeed, odor responses of an olfactory receptor neuron already decrease after a few seconds of continued stimulation with an odorant. This process is called adaptation and includes several processes terminating the depolarizing receptor current: Firstly, calcium ions flowing into the cell bind calmodulin and the ensuing $\mathrm{Ca}^{2+} /$ calmodulin complex binds to CNG channels, reducing their sensitivity to cAMP and consequently leading to closure of the channels, i.e. an interruption of the odor response. Simultaneously, a $\mathrm{Ca}^{2+} /$ calmodulin-dependent phosphodiesterase contributes to the termination of the odor response by hydrolysing cAMP. Additionally, a $\mathrm{Ca}^{2+} /$ calmodulindependent kinase appears to phosphorylate and thereby inhibit ACIII directly. Moreover, the olfactory receptors themselves are phosphorylated by receptor-dependent kinases leading to binding of arrestins and subsequent steric uncoupling of receptor/G protein interactions, thereby terminating the odor response of the receptors. Arrestins are also seminal in the internalization of olfactory receptors leading to reduced numbers of receptor molecules in the plasma membrane and thus to a reduced odor response duration of the receptor neurons $[26,27,43]$.

The multitude of mechanisms aimed at a rapid termination of signal transduction events suggests that olfactory receptor neurons are not suited to long contin- 
uous activation, but to repetitive stimuli of individually short duration.

\section{Electrical properties of olfactory receptor neurons}

Activation of olfactory receptors launches a signal transduction cascade that generates a depolarizing receptor potential, which above a certain threshold potential initiates a volley of action potentials that are propagated by the axons of the receptor neurons into the olfactory bulb. The electrical capacity of receptor neurons is in the range of $0.7-35 \mathrm{pF}$ and their electrical resting resistance amounts to $1-40 \mathrm{G} \Omega$. Resting membrane potential is between -85 and $-70 \mathrm{mV}$, and the membrane time constant ranges from 40 to over $100 \mathrm{~ms}$ [56]. With such electrical properties theoretically very few odorant molecules need to be bound to activate a receptor neuron. However, due to the comparatively low affinity of many odorants to their receptors the life time of receptor-odorant complexes is usually very short, below $1 \mathrm{~ms}$ and consequently the probability for any particular binding event to activate the signal transduction cascade is still very small [5]. On the other hand, normal physiological odor concentrations for OR receptors are in the micromolar range [51], which amounts to several million odorant molecules per second that make contact with a single cilium containing many olfactory receptor molecules. Thus in total the probability is rather high that at least some productive ligand-receptor interactions do occur. About $20-35$ productive odorant binding events seem to be sufficient to activate a receptor neuron above threshold $[3,5]$. Interestingly, the total amplification factor in this cascade is very low, in stark contrast to e.g. rod phototransduction, and for each activated receptor only a single activated $\mathrm{G}$ protein-ACIII complex may be formed [3].

The situation is different for vomeronasal neurons that react to pheromone concentrations as low as $0.1 \mathrm{pM}$ [8]. Such low concentrations amount to only a few odorant molecules per second reaching the olfactory receptors of a single cell. Consequently the affinity of pheromones to their receptors should be very high so that the life time of the receptor-pheromone complex is long enough to nevertheless generate a sufficient number of productive transduction events to activate the vomeronasal receptor neurons.

Olfactory receptor neurons tend to exhibit a certain basal activity, i.e. even in resting phases, without binding of odorants, they show a definite spike frequency. This basal acitivty might be caused by a high basal G protein or ACIII activity, but a recent study shows the olfactory receptors themselves as the probable source of receptor neuron spontaneous activity [48], with different receptors eliciting different amounts of spontaneous activity. In this way, olfactory receptors may therefore not only detemine the odor selectivity of a receptor neuron, but furthermore impress a unique identity with respect to basal activity. Basal acitivity of this kind allows the receptor neuron to react with inhibition towards an odor stimulus, i.e. with hyperpolarization and an ensuing decrease in basal spike frequency. Indeed, inhibitory odor responses of receptor neurons have been described in several species [56] and appear to be mediated by an odor-induced blockade of CNG channels as well as activation of $\mathrm{Ca}^{2+}$-dependent potassium channels $[56,64]$.

\section{Peripheral modulation of olfactory signals}

The olfactory epithelium has long been considered as simply the site where individual receptor neurons detect their cognate odors and transduce the information thus gained to the olfactory bulb, independent from other cells and without further processing. This over- simplistic perspective has been disproven in recent years by several observations. Firstly, over 30 different non-olfactory $\mathrm{G}$ protein-coupled and ionotropic receptors have been detected in receptor neurons from several species, among them purinergic, adrenergic, cholinergic and cannabinoid receptors. Correspondingly, acetyl choline, epinephrine, norepinephrine, cannabinoids and ATP have been shown to modulate odor responses already in the olfactory epithelium [16]. Thus the olfactory epithelium can no longer be regarded solely as the site of isolated odor sensors, but should be understood as a complex neuroepithelium, whose cell types exhibit mutual interactions.

The odor sensitivity of mouse olfactory receptor neurons is decreased by ATPevoked activation of purinergic receptors $\left(\mathrm{P}_{2} \mathrm{X}\right.$ and $\left.\mathrm{P}_{2} \mathrm{Y}\right)$, and conversely, odor responses are intensified by an inhibition of purinergic receptors (• Fig. 3; [19]). It has been speculated that an injury-induced release of ATP might reduce the general activity level in the olfactory epithelium, which could contribute to a more rapid recovery of the injured tissue. Consistent with this idea, another experiment shows inhibition of purinergic receptors in larval Xenopus laevis to reduce the neuronal stem cell proliferation rate in the olfactory epithelium. In other words, ATP might further proliferation and thereby post-lesion regeneration (• Fig. 3; [18]).

Cannabinoids enhance and cannabinoid antagonists suppress odor responses of Xenopus olfactory receptor neurons, presumably via CB-1 cannabinoid receptors on receptor neuron dendrites (- Fig. 3; [9]). The corresponding endocannabinoid was identified as 2-arachidonoylglycerol, which reduces the odor detection threshold of receptor neurons and is mainly produced by supporting cells in correlation to the animal's hunger state [9]. In this way hungry animals might be able to detect lesser odor concentrations, which could be advantageous for food localization purposes.

In many species the olfactory epithelium receives autonomic innervation, both sympathetic and parasympathetic nerve endings, which release norepinephrine and acetylcholine, respectively. These substances influence supporting cells and blood vessels, but they also modulate the activity of receptor neurons (- Fig. 3). Stimulation of adrenergic as well as cholinergic receptors of olfactory receptor neurons increased odor-evoked electroolfactogram signals. Furthermore, cholinergic receptors have been detected in the ciliary membrane of receptor neurons, and form complexes with olfactory receptors [16]. 


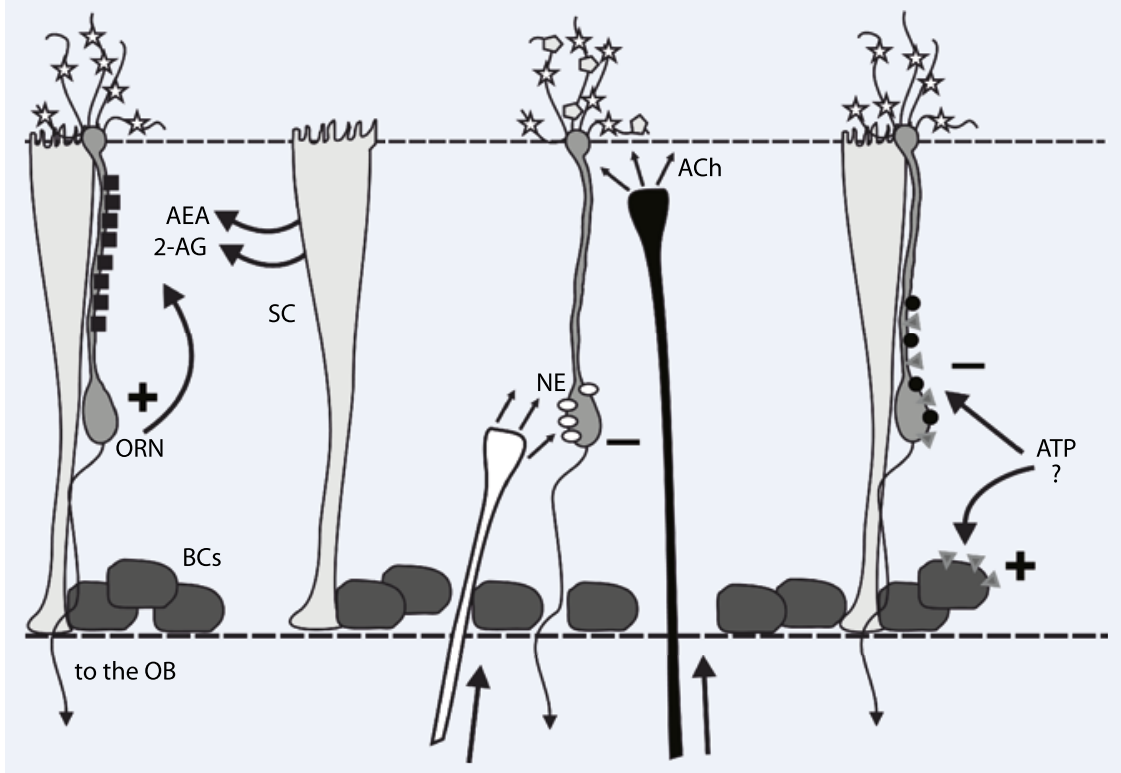

CB1 \{reduction of the odorant threshold concentration\}
P2X \{reduction of the odorant response\}
P2Y \{reduction of the odorant response; increased proliferation\}
adrenergic receptor $\{$ reduction of the odorant response\}
cholinergic receptor
OR \{odorant detection

Fig. $3 \Delta$ Peripheral modulation of odor-evoked responses. The olfactory epithelium and a selection of receptors and substances modulating olfactory information in the olfactory epithelium. A more detailed description can be found in the figure itself and in the main text. 2-AG, 2-arachidonylglycerol, Ach acetylcholine, $A E A$ arachidonylethalonamide, $A T P$ adenosintriphosphate, $B C s$ basal cells, $N E$ norepinephrine, $O B$ olfactory bulb, $O R N$ olfactory receptor neuron, $S C$ supporting cell

\section{Convergence of olfactory receptor neurons in the olfactory bulb}

Ciliated receptor neurons which express the same OR converge in a common target region in the olfactory bulb, a so-called glomerulus, which contains their synapses with the subsequent projection neurons, the mitral cells (• Fig. 4). Knockin experiments, which introduce a genetic marker under receptor-specific promoter control, have among other objectives been used to show that glomeruli are very homogenous with respect to innervating receptor neurons [66], with the exception of so-called necklace glomeruli that constitute an olfactory subsystem in the posterior olfactory bulb [11]. The spatial position of individual glomeruli is stereotypical between individuals to an accuracy of one to two glomerular diameters, both in mammals [62] and fish. In the latter, many glomeruli can be recognized on the basis of morphological cri- teria alone [2], which in mammals is only possible in a few special cases [34]. Convergence together with stereotypical positions yields a receptotopic map, in other words the receptor repertoire is mapped onto the surface of the olfactory bulb. Interestingly, this map has been duplicated in a mirror symmetrical way in rodents, so that per olfactory bulb two glomeruli are assigned to each olfactory receptor (sometimes the convergence is not perfect and the total number is a little larger). Receptors projecting to the plane of symmetry converge into unpaired glomeruli. In total one would expect over 2000 glomeruli in each olfactory bulb, roughly consistent with the anatomically determined total number of glomeruli.

Microvillous neurons show a less pronounced tendency to converge, which leads to a handful of microglomeruli as a common target region for the population of vomeronasal neurons expressing a common receptor [68]. In mammals the axons of microvillous neurons terminate in the accessory olfactory bulb, i.e. adjacent to, but clearly separate from the target regions of ciliated neurons in the main olfactory bulb. In fish target regions of ciliated and microvillous neurons are in principle also segregated, but show considerable interdigitation in a common olfactory bulb. Axons of ciliated receptor neurons, which express OR receptors, project mainly into the dorsal and medial regions of the olfactory bulb, while microvillous receptor neurons, which express $\mathrm{V}_{2} \mathrm{R}$ receptors, mainly project to the lateral part [54]. In amphibians as in mammals the microvillous receptor neurons of the vomeronasal organ project into the accessory olfactory bulb, but the microvillous receptor neurons of the main olfactory epithelium project together with the ciliated receptor neurons into the main olfactory bulb, albeit in distinct target areas.

Other olfactory organs in mammals also exhibit specialized target areas. Ciliated neurons of the Grüneberg ganglion form part of the necklace glomeruli, whereas intercalating necklace glomeruli are innervated by the GC-D-expressing neurons of the main olfactory epithelium. The ciliated neurons of the septal organ project to a small target region in the ventral olfactory bulb.

\section{Ontogenesis of the receptotopic map in the olfactory bulb}

Approximately 1000 different subpopulations of olfactory receptor neurons present a considerable challenge for the axonal pathfinding required to reach around 2000 target glomeruli. A fascinating question concerns the identity of the signal(s) that guide axons to their proper target position and that are responsible for the convergence of axons expressing the same receptor. In the mouse it has been shown that the olfactory receptors themselves, which also are localized on the axon terminals, play an important role in determining the target site of these terminals [41]. However, this may not be a direct interaction, as some experiments suggest indirect guidance via receptor-dependent cAMP signals. Each receptor may generate unique cAMP levels, which would then regulate the corresponding tran- 

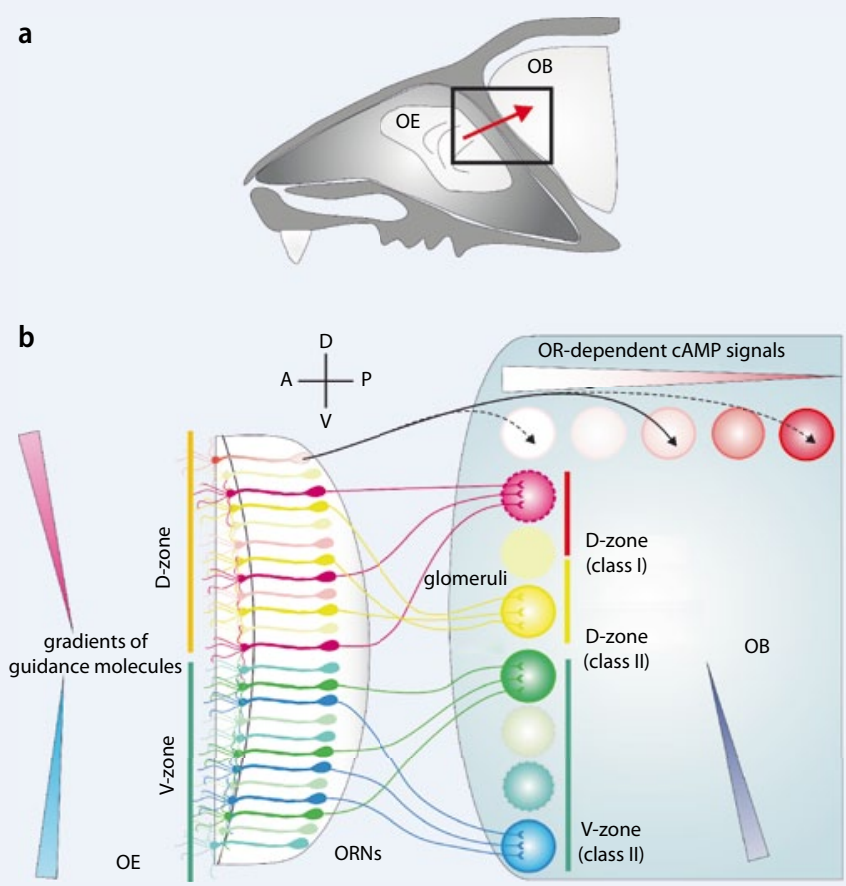

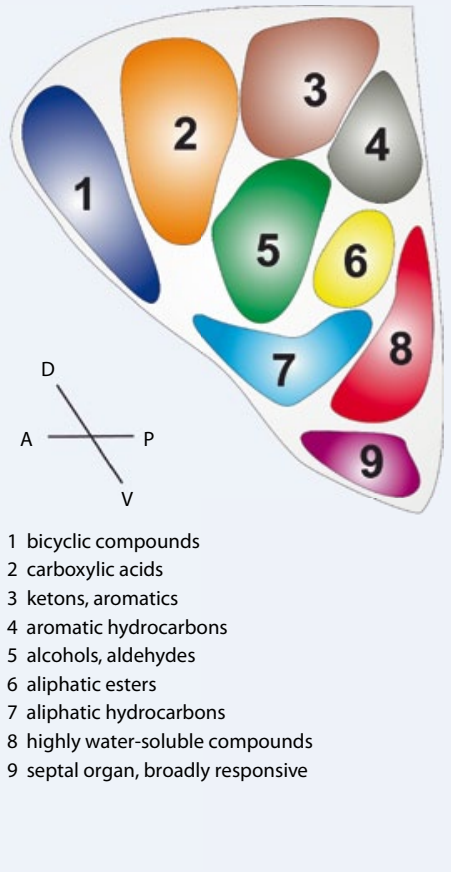

Fig. $4 \Delta$ Ontogenesis and characteristics of the glomerular map in the olfactory bulb. a A mouse skull showing the position of the olfactory epithelium $(O E)$ in the posterior nasal cavity. Axons of olfactory receptor neurons pass in small bundles through a porous bone structure (cribriform plate) to reach the olfactory bulb $(O B)$ and form synapses in glomeruli. b Axonal convergence of receptor neurons expressing the same receptor (indicated here by the same color) onto common glomeruli, guided by various graded signals. The axons of several thousand olfactory receptor neurons (ORNs) coalesce onto a single glomerulus, in which they interconnect with a handful of mitral cells (not shown here). A more detailed description of these processes is given in the main text. $\mathbf{C}$ A chemotopic olfactory map in the rat $\mathrm{OB}$ (data used are from odor-evoked 2-deoxyglucose labelling; see [24]). $A$ anterior, $V$ ventral, $P$ posterior, $D$ dorsal. Responses to different classes of chemical compounds are predominantly localized in particular subregions of the olfactory bulb

scription of axonal guidance molecules (- Fig. 4) and thereby indirectly determine the target coordinate on the anterior-posterior axis in the olfactory bulb.

Another group of guidance molecules seems responsible for determining the target position with respect to the dorsoventral axis of the olfactory bulb. This axis correlates with a dorso-ventral arrangement of receptor gene expression in the main olfactory epithelium. Olfactory receptor neurons from dorsal epithelial regions project their axons to the dorsal olfactory bulb, whereas ventrally situated receptor neurons project to the ventral olfactory bulb (• Fig. 4; [22, 41, 42, 52]). Thus it appears that the two-dimensional problem of target site determination is broken down into two one-dimensional problems, which appear to be solved by independent molecular mechanisms.

Finally, the coalescence of axon terminals into sharply delineated glomeruli, which may be considered the fine tuning of the projection, occurs in an activity-dependent manner, familiar from many other projections within the brain.

Axonal guidance mechanisms of olfactory receptor neurons are less well studied in lower vertebrates, but guidance molecules similar to those in the mouse appear to play an important role in zebrafish as well [38].

\section{Imaging odor responses in the olfactory bulb}

By measuring odor-evoked responses in the olfactory bulb it is possible to simultaneously analyse the activation of a multitude of glomeruli, and thereby implicitly also a multitude of the corresponding receptors.

Different imaging methods have been used, among them visualizing odorevoked 2-deoxyglucose uptake, calcium imaging with exogenous or transgenic fluorescent calcium indicators, imag- ing membrane potential by voltage-dependent dyes as well as intrinsic imaging, which quantifies odor-induced alterations in the optical properties of unstained, native olfactory bulbs $[12,13,24,44]$. Although the intrinsic signal mostly measures indirect effects such as local changes in the blood stream in the vicinity of actively firing neurons, results obtained are rather similar to those of calcium imaging performed specifically in the presynaptic axon terminals of olfactory receptor neurons [44, 47].

As described above for receptor molecules and receptor neurons, combinatorial representation is also found for the glomerular layer of the olfactory bulb. Individual odorants generally activate several glomeruli, and individual glomeruli are usually activated by several different odorants [67].

An odor may therefore be recognized by the brain as a complex activity pattern involving many glomeruli. In addition, 
temporal aspects of glomerular activation contribute to odor recognition [67]. This combined spatial and temporal encoding of odorants allows for the olfactory system to distinguish many more odorants than there are available receptors, since the potentially distinct activity patterns are unlimited for all practical purposes. Thus the limited specificity of olfactory receptors augments the coding capacity of the olfactory system tremendously.

In isolated cases highly specific and concomitantly highly sensitive glomeruli have been described, usually those responding to pheromone stimuli $[13,45]$. It appears that in these cases an optimal coding capacity has been less relevant than a drastically reduced stimulus threshold and/or a direct readout for the encoded information.

In several species a distinct chemotopy is observed for odor responses in the olfactory bulb, i.e. chemically related odorants activate glomeruli in similar subregions of the olfactory bulb (- Fig. 4; see also $[13,42]$ ). A possible explanation for this observation is that neurons with sequence-related receptors may often respond to similar odors and may also possess similar guidance instructions for positional information of their glomeruli.

\section{Odorants and behavior}

A vast number of behaviors are regulated by the sense of smell, from pursuit of prey or escape from predators and localization of food sources to mate choice, reproduction and multiform intraspecies communications. The importance of the olfactory sense varies with the species, but across the animal kingdom examples of odor-guided behavior abound, including mammals, reptiles, amphibians and fish. Pheromones are intraspecies chemical messengers that regulate essential behaviors such as mate choice, egg laying, nest construction, mother/child bonding, abortion, flight and agression behavior and, in mammals, are detected mainly in the vomeronasal organ $[8,65]$. Some pheromones are perceived via different olfactory subsystems, e.g. alarm pheromone by the Grüneberg ganglion [7]. Neurons from the main olfactory epithelium con- tribute to the odor-mediated control of male aggression [65].

Pheromones that influence mate choice in mice are particularly well studied. Among them are MHC peptides, known for their role in antigen presentation in the immune system, but which are also perceived by the chemosensory cells of the vomeronasal system [8], and ESP peptides that are secreted via lacrimal glands [29]. In each case a specific olfactory receptor from the $V_{2} R$ family has been identified for these peptide ligands $[15,32]$.

Another group of peptides presumably serving as olfactory signals are the formyl peptides that originate as degradation products of bacterial and mitochondrial proteins, are excreted in body secretions and may thereby convey information about diseased conspecifics or bacterial load of food sources. The receptors for these formylpeptides have been identified in mice as the fifth and smallest olfactory receptor gene family and are expressed by vomeronasal receptor neurons [49].

Steroids and prostaglandins serve as pheromones in many fish species. They are perceived by the olfactory sense and control reproductive behavior [13]. We expect that the molecular identification of pheromones and their receptors will make large strides in the coming years and that significant advances will be made in deciphering the neural networks processing the signals of activated receptor neurons up to the generation of specific behavior.

\section{Corresponding address \\ I. Manzini \\ DFG Research Center Molecular \\ Physiology of the Brain (CMPB), \\ Department of Neurophysiology and \\ Cellular Biophysics, University of Göttingen \\ Humboldtallee 23, 37073 Göttingen \\ Germany \\ imanzin@gwdg.de}

Ivan Manzini studied Biology at the University of Modena and Reggio nell' Emilia and received his doctoral degree in Neuroscience from the University of Göttingen in 2003 (Prof. Dr. Dr. Detlev Schild, Department of Neurophysiology and Cellular Biophysics). Postdoctoral training (until 2010) in the group of Prof. Dr. Dr. Detlev Schild (Department of Neurophysiology and Cellular Biophysics, University of Göttingen). At present, Ivan Manzini is an Independent Group Leader at the DFG Research Center Molecular Physiology of the Brain (CMPB) at the University of Göttingen.

\section{S. Korsching}

Institute for Genetics, University of Cologne

Zülpicher Str. 47a, 50674 Cologne

Germany

sigrun.korsching@uni-koeln.de

Sigrun Korsching studied Chemistry and Biochemistry at the Ludwigs-Maximilians-University in Munich and performed her thesis at the Max-Planck Institute for Psychiatry (now Neurobiology), department of Neurochemistry in Martinsried (scientific advisor Hans Thoenen). She received her doctoral degree from the Ludwigs-Maximilians University in Munich. Postdoctoral training (1986-1988) at the California Institute of Technology. From 1988, Independent Research Group Leader at the Max-Planck Institute for Developmental Biology in Tübingen. From 1995, Professor of Genetics at the University of Cologne.

Acknowledgement. Work in the authors' laboratories is generously supported by the DFG Research Center Molecular Physiology of the Brain (CMPB; I.M.), the DFG Priority Programme 1392 (I.M. and S.K.) and a DFG research grant to S.I.K (KO-1046/7).

\section{References}

1. Argo S, Weth F, Korsching SI (2003) Analysis of penetrance and expressivity during ontogenesis supports a stochastic choice of zebrafish odorant receptors from predetermined groups of receptor genes. Eur J Neurosci 17:833-843

2. Baier H, Korsching S (1994) Olfactory glomeruli in the zebrafish form an invariant pattern and are identifiable across animals. J Neurosci 14:219-230

3. Ben-Chaim Y, Cheng MM, Yau KW (2011) Unitary response of mouse olfactory receptor neurons. Proc Natl Acad Sci U S A 108:822-827

4. Berghard A, Dryer L (1998) A novel family of ancient vertebrate odorant receptors. J Neurobiol 37:383-392

5. Bhandawat V, Reisert J, Yau KW (2010) Signaling by olfactory receptor neurons near threshold. Proc Natl Acad Sci U S A 107:18682-18687

6. Billig GM, Pál B, Fidzinski P, Jentsch TJ (2011) $\mathrm{Ca}(2+)$-activated $\mathrm{Cl}(-)$ currents are dispensable for olfaction. Nat Neurosci 14:763-769

7. Brechbühl J, Klaey M, Broillet MC (2008) Grueneberg ganglion cells mediate alarm pheromone detection in mice. Science 321:1092-1095

8. Brennan PA, Zufall F (2006) Pheromonal communication in vertebrates. Nature 444:308-315

9. Breunig E, Czesnik D, Piscitelli F, Di Marzo V, Manzini I, Schild D (2010) Endocannabinoid modulation in the olfactory epithelium. Results Probl Cell Differ 52:139-145

10. Chao YC, Cheng CJ, Hsieh HT, Lin CC, Chen CC, Yang RB (2010) Guanylate cyclase-G, expressed in the Grueneberg ganglion olfactory subsystem, is activated by bicarbonate. Biochem J 432:267-273

11. Cockerham RE, Puche AC, Munger SD (2009) Heterogeneous sensory innervation and extensive intrabulbar connections of olfactory necklace glomeruli. PLoS One 4:e4657

12. Friedrich RW, Korsching SI (1997) Combinatorial and chemotopic odorant coding in the zebrafish olfactory bulb visualized by optical imaging. Neuron 18:737-752 
13. Friedrich RW, Korsching SI (1998) Chemotopic, combinatorial, and noncombinatorial odorant representations in the olfactory bulb revealed using a voltage-sensitive axon tracer. J Neurosci 18:99779988

14. Grosmaitre $X$, Fuss SH, Lee AC, Adipietro KA, Matsunami H, Mombaerts P, Ma M (2009) SR1, a mouse odorant receptor with an unusually broad response profile. J Neurosci 29:14545-14552

15. Haga S, Hattori T, Sato T et al (2010) The male mouse pheromone ESP1 enhances female sexual receptive behaviour through a specific vomeronasal receptor. Nature 466:118-122

16. Hall RA (2011) Autonomic modulation of olfactory signaling. Sci Signal 4:pe1

17. Hamdani el H, Døving KB (2007) The functional organization of the fish olfactory system. Prog Neurobiol 82:80-86

18. Hassenklöver T, Schwartz P, Schild D, Manzini I (2009) Purinergic signaling regulates cell proliferation of olfactory epithelium progenitors. Stem Cells 27:2022-2031

19. Hegg CC, Greenwood D, Huang W, Han P, Lucero MT (2003) Activation of purinergic receptor subtypes modulates odor sensitivity. J Neurosci 23:8291-8301

20. Hengl T, Kaneko H, Dauner K, Vocke K, Frings $S$, Möhrlen F (2010) Molecular components of signal amplification in olfactory sensory cilia. Proc Natl Acad Sci U S A 107:6052-6057

21. Hussain A, Saraiva LR, Korsching SI (2009) Positive Darwinian selection and the birth of an olfactory receptor clade in teleosts. Proc Natl Acad Sci U S A 106:4313-4318

22. Imai T, Sakano H, Vosshall LB (2010) Topographic mapping - the olfactory system. Cold Spring Harb Perspect Biol 2:a001776

23. Ishii T, Mombaerts P (2011) Coordinated coexpression of two vomeronasal receptor V2R genes per neuron in the mouse. Mol Cell Neurosci 46:397408

24. Johnson BA, Leon M (2007) Chemotopic odorant coding in a mammalian olfactory system. J Comp Neurol 503:1-34

25. Katada S, Hirokawa T, Oka Y, Suwa M, Touhara K (2005) Structural basis for a broad but selective ligand spectrum of a mouse olfactory receptor: mapping the odorant-binding site. J Neurosci 25:1806-1815

26. Kato A, Touhara K (2009) Mammalian olfactory receptors: pharmacology, $\mathrm{G}$ protein coupling and desensitization. Cell Mol Life Sci 66:3743-3753

27. Kaupp UB, Seifert R (2002) Cyclic nucleotide-gated ion channels. Physiol Rev 82:769-824

28. Keller A, Zhuang H, Chi Q, Vosshall LB, Matsunami $H(2007)$ Genetic variation in a human odorant receptor alters odour perception. Nature 449:468472

29. Kimoto H, Sato K, Nodari F, Haga S, Holy TE, Touhara K (2007) Sex- and strain-specific expression and vomeronasal activity of mouse ESP family peptides. Curr Biol 17:1879-1884

30. Korsching S (2009) The molecular evolution of teleost olfactory receptor gene families. Results Probl Cell Differ 47:37-55

31. Kurland MD, Newcomer MB, Peterlin Z, Ryan $K$, Firestein S, Batista VS (2010) Discrimination of saturated aldehydes by the rat 17 olfactory receptor. Biochemistry 49:6302-6304

32. Leinders-Zufall T, Ishii T, Mombaerts P, Zufall F, Boehm T (2009) Structural requirements for the activation of vomeronasal sensory neurons by $\mathrm{MHC}$ peptides. Nat Neurosci 12:1551-1558
33. Liberles SD, Horowitz LF, Kuang D et al (2009) Formyl peptide receptors are candidate chemosensory receptors in the vomeronasal organ. Proc Natl Acad Sci U S A 106:9842-9847

34. Luo M (2008) The necklace olfactory system in mammals. J Neurogenet 22:229-238

35. Magklara A, Yen A, Colquitt BM et al (2011) An epigenetic signature for monoallelic olfactory receptor expression. Cell 145:555-570

36. Manzini I, Schild D (2009) Olfactory coding in larvae of the African clawed frog xenopus laevis. In: Menini A (eds) The neurobiology of olfaction. CRC Press, Taylor and Francis Group, Boca Raton, pp 113-119

37. Miyamichi K, Serizawa S, Kimura HM, Sakano H (2005) Continuous and overlapping expression domains of odorant receptor genes in the olfactory epithelium determine the dorsal/ventral positioning of glomeruli in the olfactory bulb. J Neurosci 25:3586-3592

38. Miyasaka N, Sato Y, Yeo SY, Hutson LD, Chien CB, Okamoto H, Yoshihara Y (2005) Robo2 is required for establishment of a precise glomerular map in the zebrafish olfactory system. Development 132:1283-1293

39. Mombaerts P (2004a) Genes and ligands for odorant, vomeronasal and taste receptors. Nat Rev Neurosci 5:263-278

40. Mombaerts P (2004b) Odorant receptor gene choice in olfactory sensory neurons: the one receptor-one neuron hypothesis revisited. Curr Opin Neurobiol 14:31-36

41. Mombaerts $P$ (2006) Axonal wiring in the mouse olfactory system. Annu Rev Cell Dev Biol 22:713737

42. Mori K, Sakano H (2011) How is the olfactory map formed and interpreted in the Mammalian brain? Annu Rev Neurosci 34:467-499

43. Munger SD, Leinders-Zufall T, Zufall F (2009) Subsystem organization of the mammalian sense of smell. Annu Rev Physiol 71:115-140

44. Murthy VN (2011) Olfactory maps in the brain. Annu Rev Neurosci 34:233-258

45. Nara K, Saraiva LR, Ye X, Buck LB (2011) A largescale analysis of odor coding in the olfactory epithelium. J Neurosci 31:9179-9191

46. Oka Y, Korsching SI (2011) Shared and unique G alpha proteins in the zebrafish versus mammalian senses of taste and smell. Chem Senses 36:357365

47. Pain F, L'heureux B, Gurden H (2011) Visualizing odor representation in the brain: a review of imaging techniques for the mapping of sensory activity in the olfactory glomeruli. Cell Mol Life Sci 68:2689-2709

48. Reisert J (2010) Origin of basal activity in mammalian olfactory receptor neurons. J Gen Physiol 136:529-540

49. Rivière S, Challet L, Fluegge D, Spehr M, Rodriguez I (2009) Formyl peptide receptor-like proteins are a novel family of vomeronasal chemosensors. Nature 459:574-577

50. Rodriguez I, Greer CA, Mok MY, Mombaerts P (2000) A putative pheromone receptor gene expressed in human olfactory mucosa. Nat Genet 26:18-19

51. Saito $\mathrm{H}$, Chi Q, Zhuang $\mathrm{H}$, Matsunami $\mathrm{H}$, Mainland JD (2009) Odor coding by a mammalian receptor repertoire. Sci Signal 2:ra9

52. Sakano $\mathrm{H}$ (2010) Neural map formation in the mouse olfactory system. Neuron 67:530-542

53. Saraiva LR, Korsching SI (2007) A novel olfactory receptor gene family in teleost fish. Genome Res 17:1448-1457
54. Sato Y, Miyasaka N, Yoshihara Y (2005) Mutually exclusive glomerular innervation by two distinct types of olfactory sensory neurons revealed in transgenic zebrafish. J Neurosci 25:4889-4897

55. Sato Y, Miyasaka N, Yoshihara Y (2007) Hierarchical regulation of odorant receptor gene choice and subsequent axonal projection of olfactory sensory neurons in zebrafish. J Neurosci 27:1606-1615

56. Schild D, Restrepo D (1998) Transduction mechanisms in vertebrate olfactory receptor cells. Physiol Rev 78:429-466

57. Serizawa S, Ishii T, Nakatani H et al (2000) Mutually exclusive expression of odorant receptor transgenes. Nat Neurosci 3:687-693

58. Serizawa S, Miyamichi K, Nakatani H, Suzuki M, Saito M, Yoshihara Y, Sakano H (2003) Negative feedback regulation ensures the one receptor-one olfactory neuron rule in mouse. Science 302:20882094

59. Shi P, Zhang J (2007) Comparative genomic analysis identifies an evolutionary shift of vomeronasal receptor gene repertoires in the vertebrate transition from water to land. Genome Res 17:166-174

60. Shirokova E, Schmiedeberg K, Bedner P et al (2005) Identification of specific ligands for orphan olfactory receptors. G protein-dependent agonism and antagonism of odorants. J Biol Chem 280:11807-11815

61. Shirokova E, Raguse JD, MeyerhofW, Krautwurst D (2008) The human vomeronasal type-1 receptor family: detection of volatiles and cAMP signaling in HeLa/Olf cells. FASEB J 22:1416-1425

62. Strotmann J, Conzelmann S, Beck A, Feinstein P, Breer $\mathrm{H}$, Mombaerts $\mathrm{P}$ (2000) Local permutations in the glomerular array of the mouse olfactory bulb. J Neurosci 20:6927-6938

63. Sun L, Wang H, Hu J, Han J, Matsunami H, Luo M (2009) Guanylyl cyclase-D in the olfactory $\mathrm{CO} 2$ neurons is activated by bicarbonate. Proc Natl Acad Sci U S A 106:2041-2046

64. Takeuchi H, Ishida H, Hikichi S, Kurahashi T (2009) Mechanism of olfactory masking in the sensory cilia. J Gen Physiol 133:583-601

65. Tirindelli R, Dibattista M, Pifferi S, Menini A (2009) From pheromones to behavior. Physiol Rev 89:921-956

66. Treloar HB, Feinstein $P$, Mombaerts $P$, Greer CA (2002) Specificity of glomerular targeting by olfactory sensory axons. J Neurosci 22:2469-2477

67. Wachowiak M, Shipley MT (2006) Coding and synaptic processing of sensory information in the glomerular layer of the olfactory bulb. Semin Cell Dev Biol 17:411-423

68. Wagner S, Gresser AL, Torello AT, Dulac C (2006) A multireceptor genetic approach uncovers an ordered integration of VNO sensory inputs in the accessory olfactory bulb. Neuron 50:697-709

69. Weth F, Nadler W, Korsching S (1996) Nested expression domains for odorant receptors in zebrafish olfactory epithelium. Proc Natl Acad Sci U S A 93:13321-13326

70. Yoshihara $Y$ (2009) Molecular genetic dissection of the zebrafish olfactory system. Results Probl Cell Differ 47:97-120

71. Zhang X, Marcucci F, Firestein S (2010) Highthroughput microarray detection of vomeronasal receptor gene expression in rodents. Front Neurosci 4:164 